\title{
Indoor air quality modelling and measurements of a studio apartment with a mechanical exhaust system
}

\author{
Nina Szczepanik-Ścisło ${ }^{1,}$, and Agnieszka Flaga-Maryańczyk ${ }^{1}$ \\ ${ }^{1}$ Cracow University of Technology, Department of Environmental Engineering, 24 Warszawska str. \\ 31-155 Cracow, Poland
}

\begin{abstract}
The aim of the research were measurements and an attempt to model the indoor air quality (IAQ) within a studio apartment with a mechanical exhaust system, manually controlled by the occupants. The authors based the modelling on the occupancy schedule of the family members and the recorded operation duration of the ventilation system. The purpose of the performed analysis was to answer the question if it is possible and to what extent to reflect numerically the conditions within the tested object. The authors studied also the carbon dioxide level in the context of controlling the system by the residents. The simulations were carried out using the CONTAM software, developed by NIST (National Institute of Standards and Technology).
\end{abstract}

\section{Introduction}

The level and improvement of indoor air quality (IAQ) is an on-going subject that is the topic of interest for researchers around the world for both residential and non-residential buildings [1-9]. Lan and Lian [2] proved the level of indoor air quality and thermal regulation influences the quality of sleep while Madureira et al. [9] conducted a study to connect the indoor air quality in schools and its relationship with children's respiratory symptoms. The studies show that the quality of the indoor air is an important factor for human health. It is an extremely important subject in buildings that depend on mechanical ventilation systems for fresh, clean air as they may not be properly equipped, designed or controlled. Such a case was described in the work by Awbi [11] were the air quality and energy efficiency changed depending on the type ventilation system and its situation.

The danger of poor air quality is also rising due to energy saving methods by tightening of the building envelope to lessen heat loses through it. Langer et al. [10] studied the air quality in both passive and conventionally built houses and found that the quality of the indoor environment in the newly built passive dwellings was comparable to or better than in the conventionally built new houses with a mechanical ventilation system, however both may pose a threat to the thermal comfort. The trend for energy savings is very strong in the European Union as it is additionally pushed by EU directives [12].

\footnotetext{
* Corresponding author: nszsczepanik@pk.edu.p1
} 
Considering the trend for energy savings, natural ventilation systems (which rely on the airflow through the building envelope to supply clean air) are becoming obsolete and not adequate in context of the growing airtightness of the building envelope. Mechanical ventilation systems and hybrid systems are slowly becoming more common and replacing natural ventilation. In most cases, mechanical ventilation systems also contribute to energy savings as they are equipped with heat recovery systems that used the energy from the discharged air to pre-heat/pre-cool the fresh air. However, often the users of mechanical ventilation systems do not know how to regulate them, the principals for maintaining thermal comfort and the threats connected with the lack of proper ventilation. This, when the system is operated by the occupants, may lead to increased contaminant concentration and lack of thermal comfort.

In terms of indoor air quality carbon dioxide is often used as a valid air quality indicator. The average concentration in the outdoor air is $0.04 \%$ (400 ppm) which is a safe level for human occupancy. The maximum indoor concentration of carbon dioxide that should not be exceeded for hygienic reasons, recommended by ASHRAE [13] and the World Health Organization, is 1000 ppm [14]. It is also known as the Pettenkofer number. Higher concentration of $\mathrm{CO}_{2}$ has been proven to have a negative effect on human performance, perception of poor indoor air quality or prevalence of certain health symptoms such as irritation of mucous membranes, headaches or tiredness [15-21].

In modern buildings, the only indoor air source of $\mathrm{CO}_{2}$ are usually humans (respiration). The contaminant concentration shows the correlation between occupancy schedules and the efficiency of the ventilation system (the impact of human activity on the inside air quality). The studies presented earlier show that inside $\mathrm{CO}_{2}$ concentration is an ongoing problem. This is especially important in buildings with mechanical ventilation controlled by residents, according to their daily routine, as in analysed studio apartment. To determine if such systems provide proper indoor air quality (IAQ) the measurements of $\mathrm{CO}_{2}$ concentration were done. Apart from measurements, that showed the air quality and its correlation to the operation of the ventilation system, a series of numerical simulations were carried out as an attempt to model the indoor air quality in the analysed object. The simulations were based on the occupancy schedule of the family members and the operation duration of the ventilation system that was recorded during experiment. The simulations were carried out using the CONTAM software, developed by NIST (National Institute of Standards and Technology).

\section{Methods}

\subsection{Real measurements and test object}

The test object was a small $\left(35 \mathrm{~m}^{2}\right)$ studio apartment (Fig. 1) located in Krakow, Poland. It consisted of a bathroom and one large room serving as a living room, bedroom and kitchen. The apartment was equipped with three outlet mechanical vents, two located in the large room and one in the bathroom. Above the windows humidity sensitive air inlets were installed so that fresh air could flow into the system. The air was discharged by mechanical outlet vents. The vents were manually controlled by the occupants, and could be turned off entirely if they did not meet the thermal needs of the residents e.g. when creating drafts.

During the study, the apartment was occupied by a family of three (two adults and one 2-year-old child), who were the only indoor source of carbon dioxide $\left(\mathrm{CO}_{2}\right)$ - chosen as an indoor air quality indicator. The heating needs were supplied by a district heating system and cooking was carried out on an electric cooker. 
Because the ventilation system was controlled manually, without any feedback about the inside contaminant concentration or thermal conditions, it posed a potential threat to the hygienic conditions as contaminant levels could be exceeded when the ventilation system was not used at full capacity.

To determine the air quality in the analysed studio apartment, measurements were conducted, showing how the real concentration of $\mathrm{CO}_{2}$ changed. The experiment was carried out for a period of one week (seven days) during the winter season. To measure the concentration of $\mathrm{CO}_{2}$, two wireless sensors were placed inside of the apartment (one in the living room and one in the bathroom). They were placed in the centre of the rooms to measure the average concentration inside each of them. The measurement was carried out continuously under real time conditions in both the day and night. While measuring occurred the inhabitants moved freely inside the building. The sensors traced the measured parameter every 30 seconds. The range of installed sensors in terms of carbon dioxide concentration was $0-5000 \mathrm{ppm}$ and their accuracy was $\pm 20 \mathrm{ppm}$.

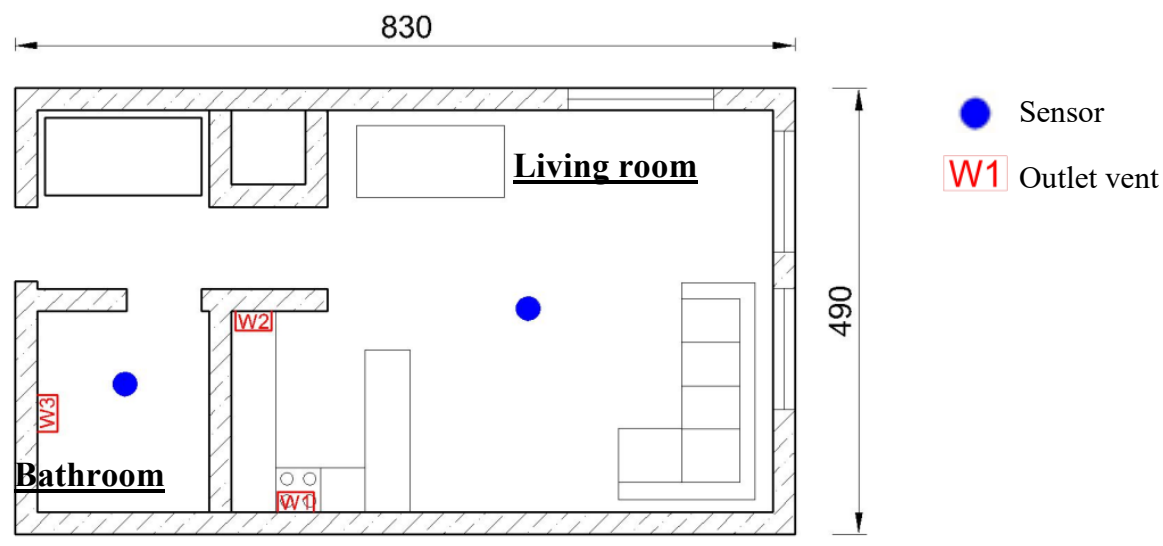

Fig. 1. Layout of the test object.

\subsection{Simulation methods}

The simulations were carried out using the CONTAM software. The program was created by NIST (National Institute of Standards and Technology) and may be used for a variety of applications for example: assessing the adequacy of ventilation rates in a building, determining the variation in ventilation rates over time, for determining the distribution of ventilation air within a building, for estimating the impact of envelope air-tightening efforts on infiltration rates, and for evaluating the energy impacts of building airflows [22]. CONTAM divides the structure into well mixed zones. It treats each zone as a single nod, in which the air has a uniform structure. Air is assumed to be an ideal gas which properties are computed from the ideal gas law.

It has been used by authors of many studies to determine the contaminant levels and test different types of ventilation systems [23-29] which is why it was chosen for this study. Hamdani et al. [26] used the program to study the effect of natural ventilation on the indoor air quality. Hurnik et al. [27] conducted simulations using CONTAM to calculate ventilation airflows for residential houses equipped with hybrid ventilation systems. Pinto et al. [25] used the program to perform a sensitivity study of mixed ventilation systems in residential buildings. The mentioned studies show the wide applicability of CONTAM software in analysing air quality problems. Based on the presented research, the study 
in this paper tried to answer the question if it is possible to reflect numerically the conditions within the tested object, especially in reference to the occupancy schedule and the recorded operation duration of the ventilation system.

To determine the conditions within the test object, the occupants were asked to fill out an occupancy schedule plan that included their occupancy schedule, information which vent was tuned on and also any potential sources of additional contaminants (e.g. baths as a source of water vapour). An example of such a schedule is shown in table 1; such a table was filed out for each test day. It was agreed that in the column that was assigned as the number of occupants, each additional adult occupant would be equal to 1 and the child would be equal to 0.5 . This was important as to determine the carbon dioxide emission rate from the occupants for further simulations. The outlet vent numbers were assigned as in the simulations and as is shown in figure 1 . The capacity of the vents were:

- Vent no. $1-100 \mathrm{~m}^{3} / \mathrm{h}-1.2$ exchange per hour

- Vent no. $2-25 \mathrm{~m}^{3} / \mathrm{h}-0.3$ exchange per hour

- Vent no. $3-25 \mathrm{~m}^{3} / \mathrm{h}-0.3$ exchange per hour

While analysing the occupant logs, it turned out that vent no. 3 (in the bathroom) was turned on all the time generating 0.3 air exchanges per hour, vent no 2 was tuned on only three times while vent no. 1 was activated twice, but only for a period of 5 minute each time. This was due to the vents impact on the thermal comfort of residents. When tuned on, the vents crated a draft in the large room that was unpleasant for the occupants, so they preferred simply to turn it off.

Table 1. Example of occupancy schedules and ventilation patterns noted by the occupants.

\begin{tabular}{|c|c|c|c|c|c|}
\hline $\begin{array}{c}\text { Hour of the } \\
\text { day }\end{array}$ & $\begin{array}{c}\text { Vent no. } \\
\mathbf{1}\end{array}$ & $\begin{array}{c}\text { Vent no. } \\
\mathbf{2}\end{array}$ & Vent no. 3 & $\begin{array}{c}\text { No. of } \\
\text { occupants }\end{array}$ & $\begin{array}{c}\text { Comments/additional } \\
\text { information }\end{array}$ \\
\hline $7: 00$ & - & - & + & 2.5 & \\
\hline $7: 50$ & - & - & + & 1.5 & \\
\hline $12: 45$ & - & - & + & 0 & \\
\hline $15: 55$ & - & - & + & 1.5 & $\begin{array}{c}\text { Open window for } \\
\text { min. }\end{array}$ \\
\hline $16: 55$ & + & - & + & 2.5 & \\
\hline $17: 00$ & - & - & + & 2,5 & \\
\hline $17: 45$ & - & - & + & 1.5 & \\
\hline $23: 33$ & - & - & + & 2.5 & \\
\hline
\end{tabular}

The layout of the apartment generated in the program is shown in figure 2. The outlet and inlet vents were also included in the numerical simulation and had the same characteristics as in the measurements: air flow magnitude and activation in the same time frame.

For numerical simulation it was assumed based on [30] that the adults generated $0.004 \mathrm{~L} / \mathrm{s}$ of $\mathrm{CO}_{2}$ while the child exhaled $0.0025 \mathrm{~L} / \mathrm{s}$ of $\mathrm{CO}_{2}$. During the night (while sleeping) the occupants generated $66 \%$ of this amount due to slower respiration. 


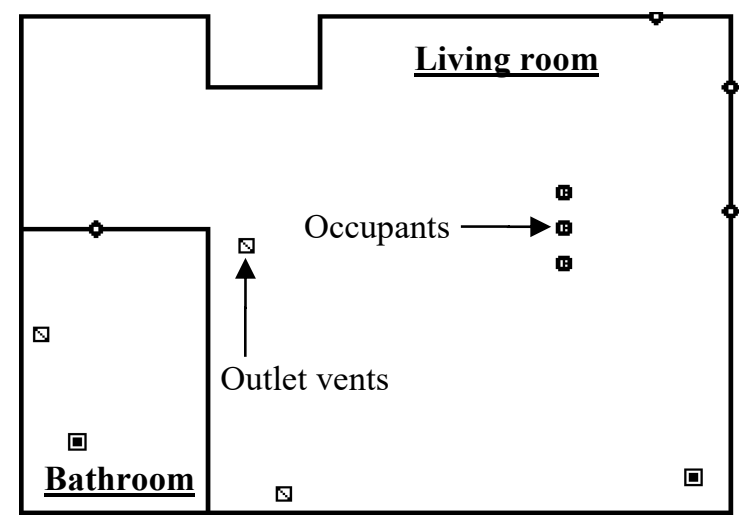

Fig. 2. Layout of the test object in the CONTAM simulation program.

\section{Results}

\subsection{Living room}

The results of conducted measurements and simulations for the large living space are shown in figure 3, where the recommended hygienic level is marked at $1000 \mathrm{ppm}$. The concentration of $\mathrm{CO}_{2}$ rises during the night and lowers during the day when the occupants are out of the house. However, the concentration of the contaminant was for the majority of time over the maximum hygienic level of $1000 \mathrm{ppm}$, recommended by ASHRAE [13] and the World Health Organization. The highest peaks can be noted during the morning (from 6 am to $10 \mathrm{am}$ ) and the evening (5 pm to $11 \mathrm{pm}$ ). During this time, the family was inside of the test apartment and contributed to the high concentration of $\mathrm{CO}_{2}$. The largest $\mathrm{CO}_{2}$ peak was on the $16^{\text {th }}$ of December at $4 \mathrm{pm}$ when the concentration reached up to almost $2000 \mathrm{ppm}$. According to the occupant logs, during this time only one outlet vent was tuned on (vent no. 3 in the bathroom) and all of the family was in the apartment. The concentrations of $\mathrm{CO}_{2}$ lowered when the occupants were out of the building (during the afternoon) but fell under 1000ppm for only a period of a few hours.

The results also show that the simulated values reflect the measured conditions within the apartment and are characterised by similar fluctuations as the measurements. To determine the accuracy of the simulation the mean absolute percentage error (MAPE) was calculated. For the living room the MAPE was equal to $12.9 \%$. 


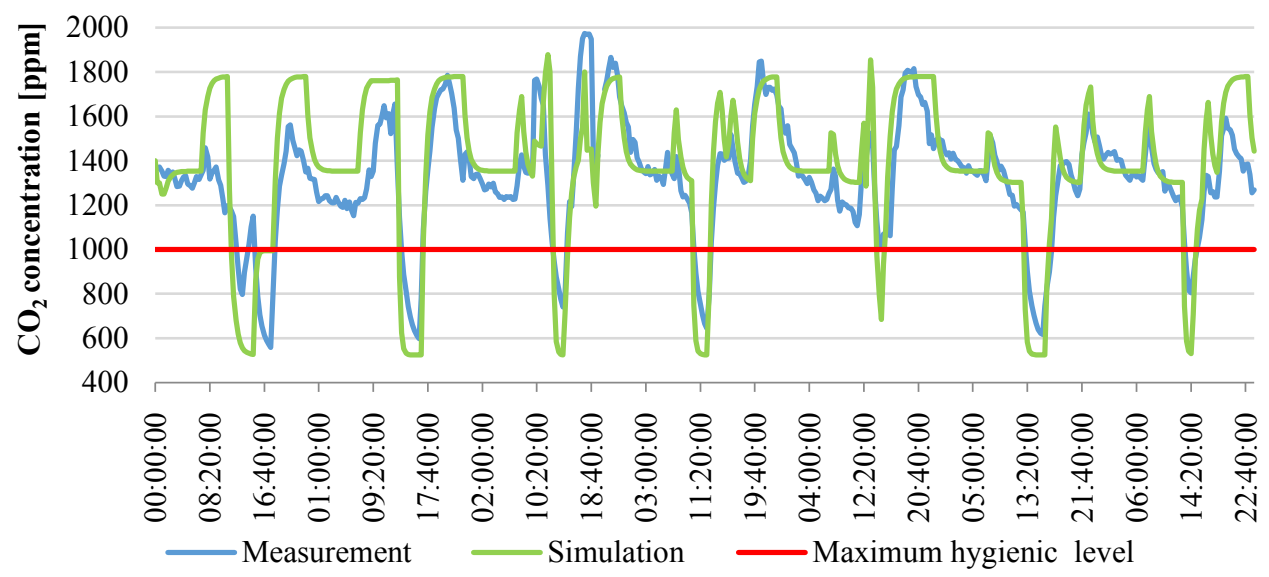

Fig. 3. Contaminant concentration results for the living room.

\subsection{Bathroom}

The results of conducted measurements and simulations from the bathroom space are shown in figure 4, where the recommended hygienic level is marked at $1000 \mathrm{ppm}$. The fluctuations of $\mathrm{CO}_{2}$ are similar to the ones in the living room as the concentration of the contaminate rises during the night and lowers during the day. Even though the contaminant peaks are lower than in the living room (by around $200 \mathrm{ppm}$ ), they still exceeded the maximum recommended hygienic level of $1000 \mathrm{ppm}$. The peaks and lows of the $\mathrm{CO}_{2}$ concentration occur in roughly the same time as the ones in the living room reaching a maximum of around $1800 \mathrm{ppm}$. As higher concentration of $\mathrm{CO}_{2}$ has been proven to have a negative effect on humans such peaks may not be indifferent for the family as they last for substantial periods of time - up to 20 hours.

Once again, the results show that the simulation quite well reflects the conditions within the test object and has similar fluctuations as the real measurements. The mean absolute percentage error (MAPE) calculated for the bathroom was higher than for the living room, reaching $17.5 \%$. This may be caused by the irregular usage of the room thought the day, as the majority of time the occupants spent in the living room.

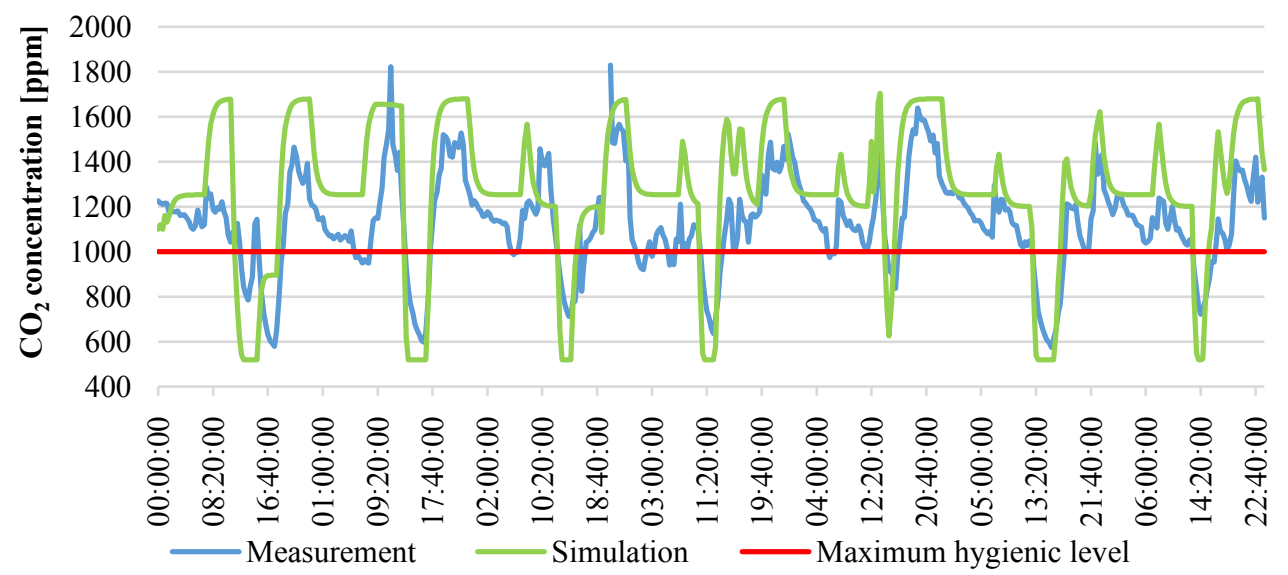

Fig. 4. Contaminant concentration results for the bathroom. 


\section{Discussion}

The results show that the air quality inside the tested apartment was poor. As higher concentration of $\mathrm{CO}_{2}$ has been proven to have a negative effect on humans, such elevated $\mathrm{CO}_{2}$ levels may not be indifferent for the family, especially for the 2-year-old child.

It should be pointed out that the ventilation system was controlled manually and the occupants were not aware of the contaminant levels. The occupants activated mainly the vent in the bathroom for the whole duration of the test as the rest generated the feeling of a draft which disrupted their thermal comfort feeling. It puts a question mark under the legitimacy of leaving the control of mechanical ventilation system to occupants. If the system was controlled on the basis of contaminant concentration, it would definitely improve the quality of the air. However, such systems would explicitly cost more due to the automatic system that would have to be installed.

The numerical simulation results show good correlation with the measurements (the mean absolute percentage error (MAPE) ranged from $12.9 \%$ to $17.5 \%$ ) which means that CONTAM is a valuable tool for such applications. Similar values of the MAPE coefficient were found by Pantazaras et al. [31], who measured and simulated the concentration of $\mathrm{CO}_{2}$ inside of office buildings to estimate future levels of the contaminant. Basing the modelling on the occupancy schedule of the family members allowed the proper estimation of $\mathrm{CO}_{2}$ generation rates.

\section{Conclusions}

The study focused on measurements and an attempt to model the IAQ within a studio apartment with a mechanical exhaust system, manually controlled by the occupants. The air quality modelling was based on the occupancy schedule of the family members and the recorded operation duration of the ventilation system. The purpose of the performed analysis was to answer the question to what extent is it possible to numerically reflect the conditions within the tested object. The authors studied also the carbon dioxide level in the context of the manually controlled ventilation system. The residents altered the air flow according to their sense of thermal comfort.

Carbon dioxide was used as an indicator of the air quality as the only indoor source was from human respiration and reflected the influence of the occupants activity on the IAQ. The results showed that the concentration of carbon dioxide exceeded the maximum recommended hygienic level and in the worst cases it was even doubled. The duration of the increased $\mathrm{CO}_{2}$ level lasted for substantial periods of time (up to 20 hours) and lowered only when the occupants left the apartment. Such conditions may not be indifferent in the long run for the occupants.

The numerical simulation results show good correlation with the measurements (the mean absolute percentage error (MAPE) ranged from $12.9 \%$ to $17.5 \%$ ) which means that CONTAM is a valuable tool for such applications.

\section{References}

1. G. Zucker, A. Sporr, A. Garrido-Marijuan, T. Ferhatbegovic, R. Hofmann, Energy Build. 155, 378-389 (2017)

2. L. Lan, Z. Lian, Build. Environ. 99, 252-259 (2016)

3. K. Gładyszewska-Fiedoruk, M. Nieciecki, Energy Procedia 95, 132-139 (2016)

4. Y. Chen, B. Raphael, S.C. Sekhar, Build. Environ. 96, 283-292 (2016) 
5. L.C. Ng, A.K. Persily, S.J. Emmerich, Build. Environ. 92, 627-634 (2015)

6. A. Lipczynska, J. Kaczmarczyk, A.K. Melikov, Building and Environment 92, 603-614 (2015)

7. A. Fischer, E. Ljungström, L. Hägerhed Engman, S. Langer, Indoor Air 25, 168-175 (2015)

8. H.A. Elmaghraby, E.E. Khalil, $13^{\text {th }}$ Int. Energy Convers. Eng. Conf. (2015)

9. J. Madureira, I. Paciencia, J. Rufo, E. Ramos, H. Barros, J.P. Teixeira, E. de Oliveira Fernandes, Atmos. Environ. 118, 145-156 (2015)

10. S. Langer, G. Bekö, E. Bloom, A. Widheden, L. Ekberg, Build. Environ. 93, 1, 92-100 (2015)

11. H.B. Awbi, Energy Procedia 112, 277-286 (2017)

12. Directive 2010/31/EU (2010)

13. ASHRAE, Standard 62-1989 (1989)

14. N.-T. Chao, W.-A. Wang, C.-M. Chiang, Energy Build. 29, 1, 93-105 (1998)

15. M.G.A. Christine, A. Erdmann, Indoor Air 14, 8, 127-134 (2004)

16. J.S. Park, C.H. Yoon, Indoor Air 21, 4, 284-290 (2011)

17. O.A. Seppänen, Indoor Air 9, 4, 226-252 (1999)

18. R.J. Shaughnessy, U. Haverinen-Shaughnessy, A. Nevalainen, D. Moschandreas, Indoor Air 16, 6, 465-468 (2006)

19. P. Wargocki, D.P. Wyon, J. Sundell, G. Clausen, P.O. Fanger, Indoor Air 10, 4, 222-236 (2000)

20. P. Wargocki, D.P. Wyon, Build. Environ. 59, 581-589 (2013)

21. D.P. Wyon, Indoor Air 14, 7, 92-101 (2004)

22. G. Walton, W. National Institute of Standards and Technology (2005)

23. S. Yu, L. He, G. Feng, Procedia Eng. 121, 1613-1619 (2015)

24. D. Rim, A. Persily, S. Emmerich, W.S. Dols, L. Wallace, Atmos. Environ. 69, 219-230 (2013)

25. M. Pinto, J. Viegas, V. Freitas, Energy Build. 152, 534-546 (2017)

26. M. Hamdani, T. Benouaz, M.K. Cherier, E. Renouvelables, Energy Procedia 139, 1-6 (2017)

27. M. Hurnik, A. Specjal, Z. Popiolek, Energy Build. 149, 123-132 (2017)

28. S. Goubran, D. Qi, W.F. Saleh, L. Wang, Energy Build. 138, 579-590 (2017)

29. L.C. Ng, N. Ojeda Quiles, W.S. Dols, S.J. Emmerich, Build. Environ. 127, 47-57 (2018)

30. A. Persily, A Modeling Study of Ventilation, IAQ, and Energy Impacts of Residential Mechanical Ventilation (1998)

31. A. Pantazaras, S.E. Lee, M. Santamouris, J. Yang, Energy Build. 127, 774-785 (2016) 